This item was submitted to Loughborough's Research Repository by the author.

Items in Figshare are protected by copyright, with all rights reserved, unless otherwise indicated.

\title{
Knowledge reuse in manufacturability analysis
}

PLEASE CITE THE PUBLISHED VERSION

http://dx.doi.org/10.1016/j.rcim.2007.07.003

PUBLISHER

(c) Elsevier

VERSION

AM (Accepted Manuscript)

LICENCE

CC BY-NC-ND 4.0

REPOSITORY RECORD

Cochrane, Sean D., R.I.M. Young, Keith Case, Jennifer A. Harding, James Gao, Shilpa S. Dani, and David Baxter. 2019. "Knowledge Reuse in Manufacturability Analysis". figshare. https://hdl.handle.net/2134/11300. 
This item was submitted to Loughborough's Institutional Repository (https://dspace.lboro.ac.uk/) by the author and is made available under the following Creative Commons Licence conditions.

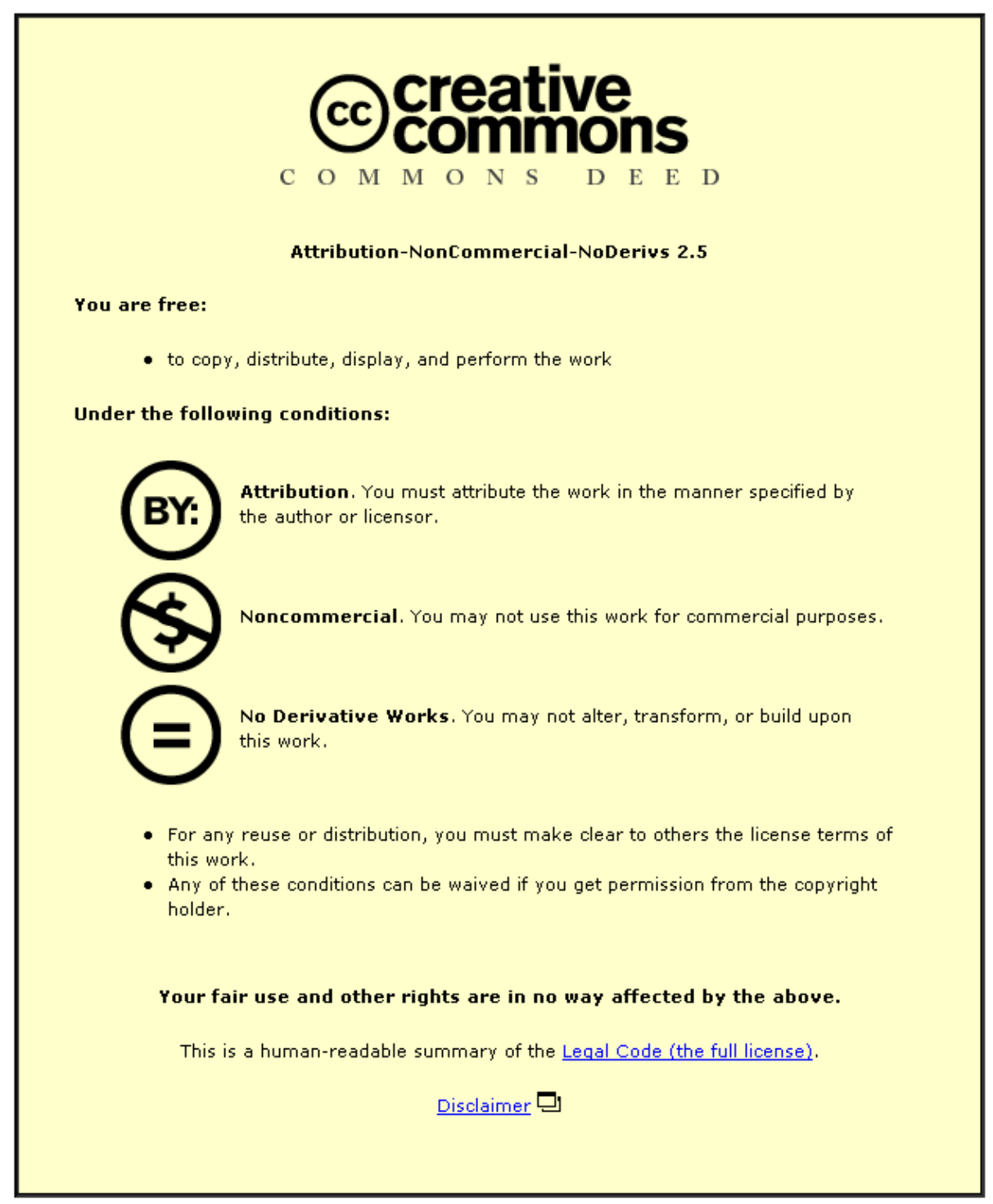

For the full text of this licence, please go to: http://creativecommons.org/licenses/by-nc-nd/2.5/ 


\title{
Knowledge Reuse in Manufacturability Analysis
}

\author{
Sean Cochrane ${ }^{\mathrm{a}}$, Robert Young ${ }^{\mathrm{a}}$, Keith Case $^{\mathrm{a}}$, Jennifer Harding ${ }^{\mathrm{a}}$, \\ James Gao ${ }^{\mathrm{b}}$, Shilpa Dani ${ }^{\mathrm{a}}$, David Baxter ${ }^{\mathrm{b}}$ \\ a Wolfson School of Mechanical and Manufacturing Engineering, Loughborough University, Leicestershire, LE11 3TU, UK \\ b Centre for Decision Engineering, Manufacturing Department, Cranfield University, Bedfordshire, MK43 0AL, UK
}

\begin{abstract}
This paper describes a set of modelling guidelines for the improved reuse of manufacturing knowledge in decision support systems. The work draws on research into product and manufacturing knowledge models, and uses a case study based on a simplified jet engine combustion chamber casing to illustrate the proposed guidelines. The paper describes three principles of reuse, i.e. the separation of information from knowledge, the separation of product knowledge from manufacturing process knowledge, and the correct classification of manufacturing knowledge. Whilst the first two principles were found to be well established in the research literature, guidance on how to apply classification hierarchies for optimum reuse was found to be insufficient. The guidelines presented in this paper therefore provide improved guidance on how to classify manufacturing knowledge for optimum reuse.
\end{abstract}

Key Words: Knowledge Representation, Knowledge Reuse, Enterprise Modelling, Ontology, Design for Manufacture.

\section{Introduction}

Substantial research effort has been pursued in Knowledge Based Systems to support manufacturability analysis in design (Maropoulos 2003). These typically require the extensive capture and representation of knowledge related to both the product being designed and its manufacturing environment (Young et al 2005). This is a time consuming and expensive undertaking, and so knowledge reuse is an important consideration when modelling enterprises.

A number of reference models and methodologies for modelling generic forms of enterprises are discussed in the research literature, e.g. RM-ODP (ISO/IEC 107461), CIMOSA (Kosanke et. al. 1999), and CommonKADS (Schreiber et. al. 1999). These describe a series of modelling stages that invariably include some form of information view, which structures

\footnotetext{
${ }^{1}$ Corresponding author: r.i.young@,lboro.ac.uk
} 
knowledge and information according to a pre-defined class hierarchy.
Facilities representations cannot be constructed independently of product

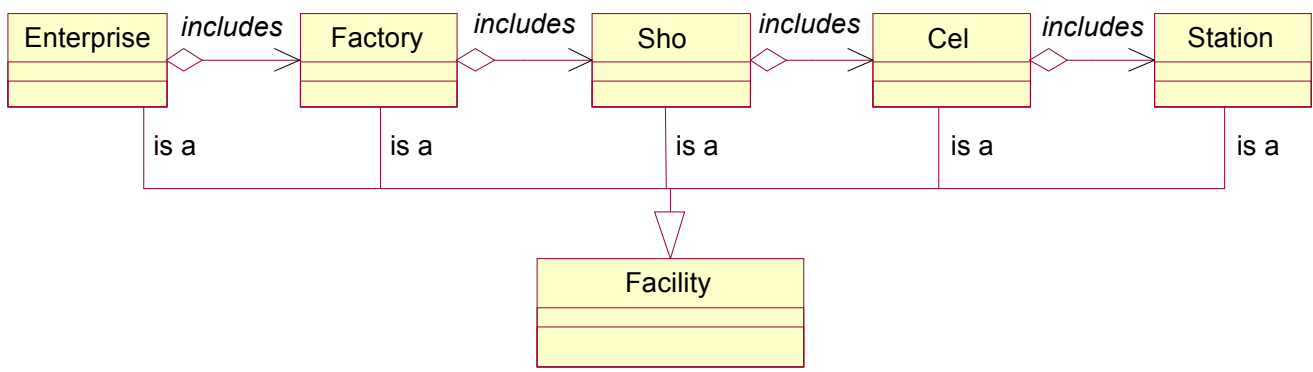

Figure 1: Facility Specialisations (Young et. al. 2000²)

Various hierarchies for product design and manufacturing environments have also representations as they are used to manufacture products. One route to linking

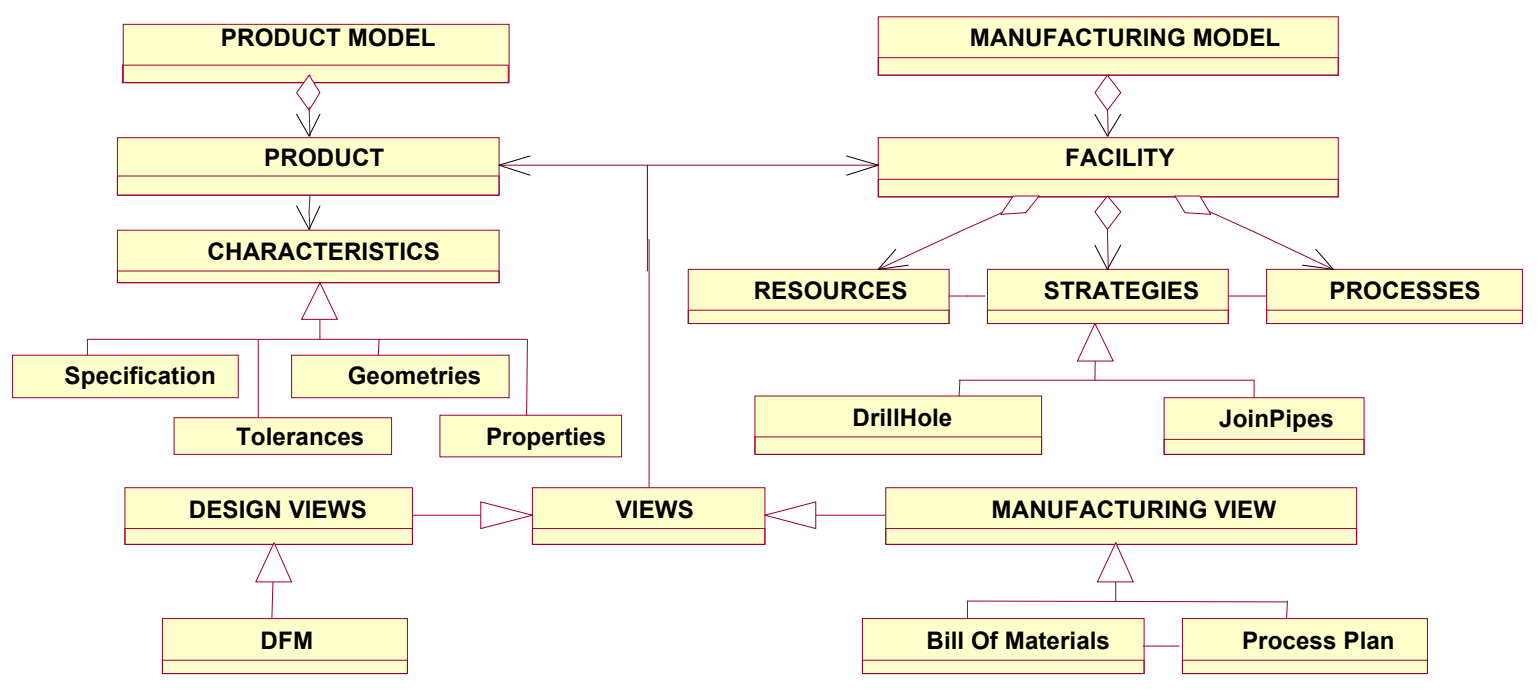

Figure 2: Design and Manufacturing Views (Zhao et. al. 2000²)

been proposed, e.g. MOKA (Oldham et. al. 1998); and "product and manufacturing models" (Molina and Bell 1999).

Molina and Bell's manufacturing model describes an enterprise as an aggregation of facilities, i.e. stations, cells, shops, and factories while facilities are described in terms of resources performing processes, under the control of manufacturing strategies. An extension of this approach by (Young et al 2000) is shown in figure 1 which extends the concept from representing an individual facility to the representation of enterprises. It also builds the model using a UML representation. facility and product representations is illustrated in figure 2, building on the work of Zhao (Zhao et al 2000).

More recent work on manufacturing facility representation has focussed on issues such as knowledge maintenance (Guerra 2004), knowledge sharing using ontologies (Lin et. al. 2004), and representing global supply chains (Liu and Young, 2004). These more recent developments do not however provide application guidelines on how to maximise the reuse of knowledge classified using the 
proposed hierarchies ${ }^{2}$. This paper provides these guidelines, and demonstrates their application through an industrial case example, based on the simplified jet engine combustor casing shown in figure 3 .

The casing is manufactured by forging a series of metallic rings which are then welded together to form the rough shape of the component. The chamber is then machined, using a variety of turning, milling, and drilling processes to create the final object (and achieve the required tolerances).

This paper identifies three principles of knowledge reuse that can be applied to the representation of the chamber and its manufacturing environment. Firstly, knowledge (in the form of rules and constraints) needs to be separated from information; Secondly, knowledge needs to be classified according to the separate product and manufacturing hierarchies shown in figure 2 .

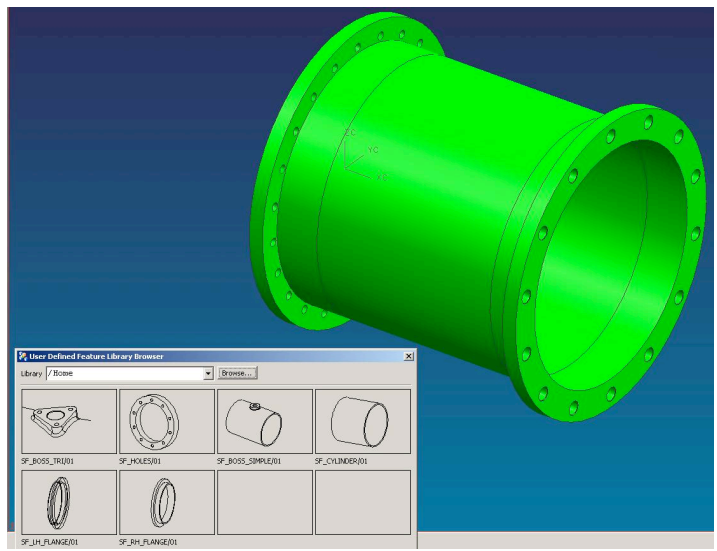

Figure 3: Simplified Combustor Casing

Finally, different layers of manufacturing strategies (describing how resources perform processes) need to be applied. The following sections explain these principles in more detail.

\footnotetext{
${ }^{2}$ The UML (figures 1 and 2) was not used by the original Molina and Bell (1999) research, but was applied by others, notably Young et. al. (2000).
}

\section{Knowledge versus Information}

Before examining why knowledge and information should be classified separately it is worth describing what is actually meant by these two terms. Information exists when the relationships between data (i.e. numbers and symbols) are recognised within a specific context. In a geometric context for example, " $5 \mathrm{~cm}$ from A" is recognised as a distance (Mills and Goossenaerts, 2001). Knowledge on the other hand, is information with added detail relating how it should be used or applied (Harding 1996). Knowledge may therefore include rules describing what actions to take when certain information exists, e.g. "sound an alarm when the distance is $5 \mathrm{~cm}$ ".

The coding example shown in figure 4 illustrates how separating knowledge from information improves reuse. Two ways of coding a machining rule typical to the manufacture of a combustion chamber are shown. The first approach hard codes information (i.e. the milling tolerance) into a rule describing when a milling process

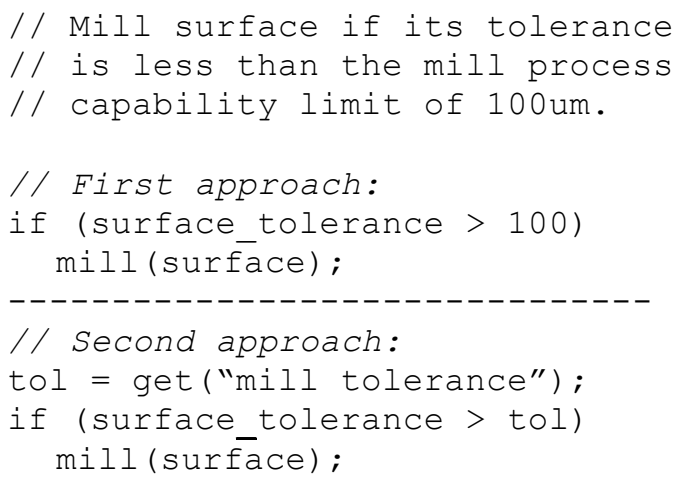

Figure 4: Coding Style Examples

should be used. The second approach declares the milling tolerance as an attribute, and accesses a separate database to retrieve the actual tolerance value.

By separating the milling tolerance (i.e. information) from the milling rule (i.e. knowledge) the second approach makes it easier to reapply the rule to different 
scenarios (e.g. machine tools and materials with different milling process capabilities).

The manufacturing model shown in figure 2 provides separate classes for manufacturing strategies, processes and resources. It is therefore important to distinguish between the strategy class (which stores knowledge of how to use resources to perform processes), and the resource and process classes which store information on relevant resources and processes. This principle is sometimes referred to as the separation of procedural knowledge from declarative information, and has been applied to the development of agent systems (Wray et. al. 2004).

\section{Product/Process Separation}

Separating product from process information is relatively straightforward (e.g. product characteristics such as diameters are clearly part of the product model). Knowledge classification may not however be quite so clear cut, and it is important to make the correct distinctions if reuse is to be maximised. Current literature describing manufacturing models provides basic classification hierarchies (see figures 1 and 2), but does not provide clear guidelines on how to make this separation. The chamber case study is therefore used below to illustrate how this can be achieved.

We may for example wish to constrain the placement of holes on the chamber, ensuring a separation in excess of $6 \mathrm{~mm}$. Such a constraint could be classified arbitrarily as being either part of the product or the manufacturing model. In reality we need to establish the reasoning behind the constraint to optimise reuse.

If the constraint is determined by the product (e.g. larger chambers require greater separation), then the chamber entity is the obvious location. Alternatively, if the separation is determined by drilling and/or boring processes, the constraint should be located in the manufacturing model. An incorrectly located constraint would prevent different product and/or process combinations from being evaluated using the same set of rules and constraints.

\section{Manufacturing Strategies}

The third reuse principle described by this paper is the classification (or layering) of manufacturing strategies. Strategies describe how resources perform processes, and form a central class in the facility representation described in figure 2 .

As an example, a simplified component level strategy for the manufacture of part of a chamber ring is illustrated by the process schematic shown in figure 5. This illustrates how a range of processes can be brought together to specify a higher level strategy for a component. Station level strategies can then be defined for each of the individual stations to be used for the various specific processes.

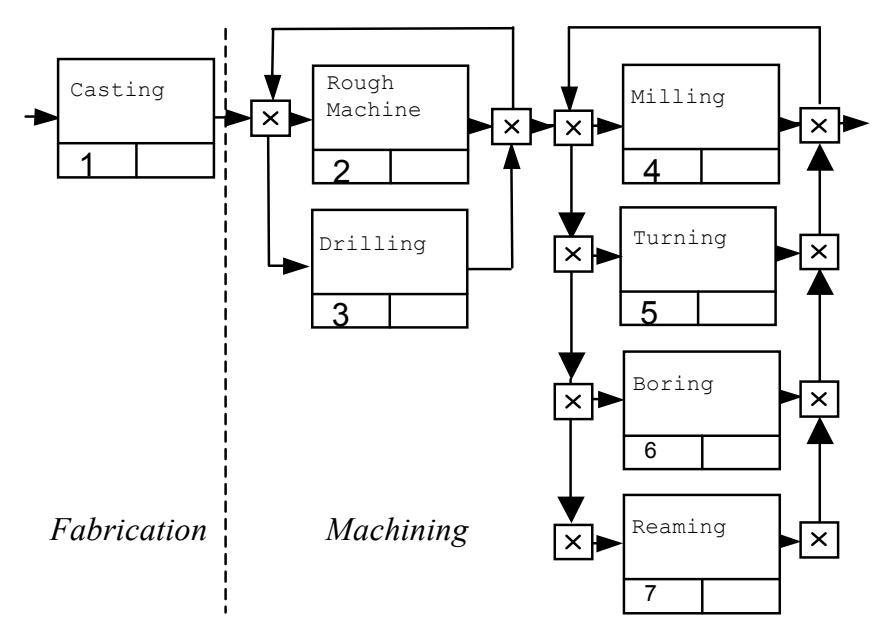
Figure 5: Part of a simplified Chamber
Manufacturing Process Schematic.

Manufacturing strategies can be classified according to layers (based on the enterprise, factory, station, and cell hierarchy shown in figure 1) as illustrated in figure 6. Low level strategies (relevant to stations and cells) describe individual processes. The scope of these strategies is limited to the creation and manipulation of 


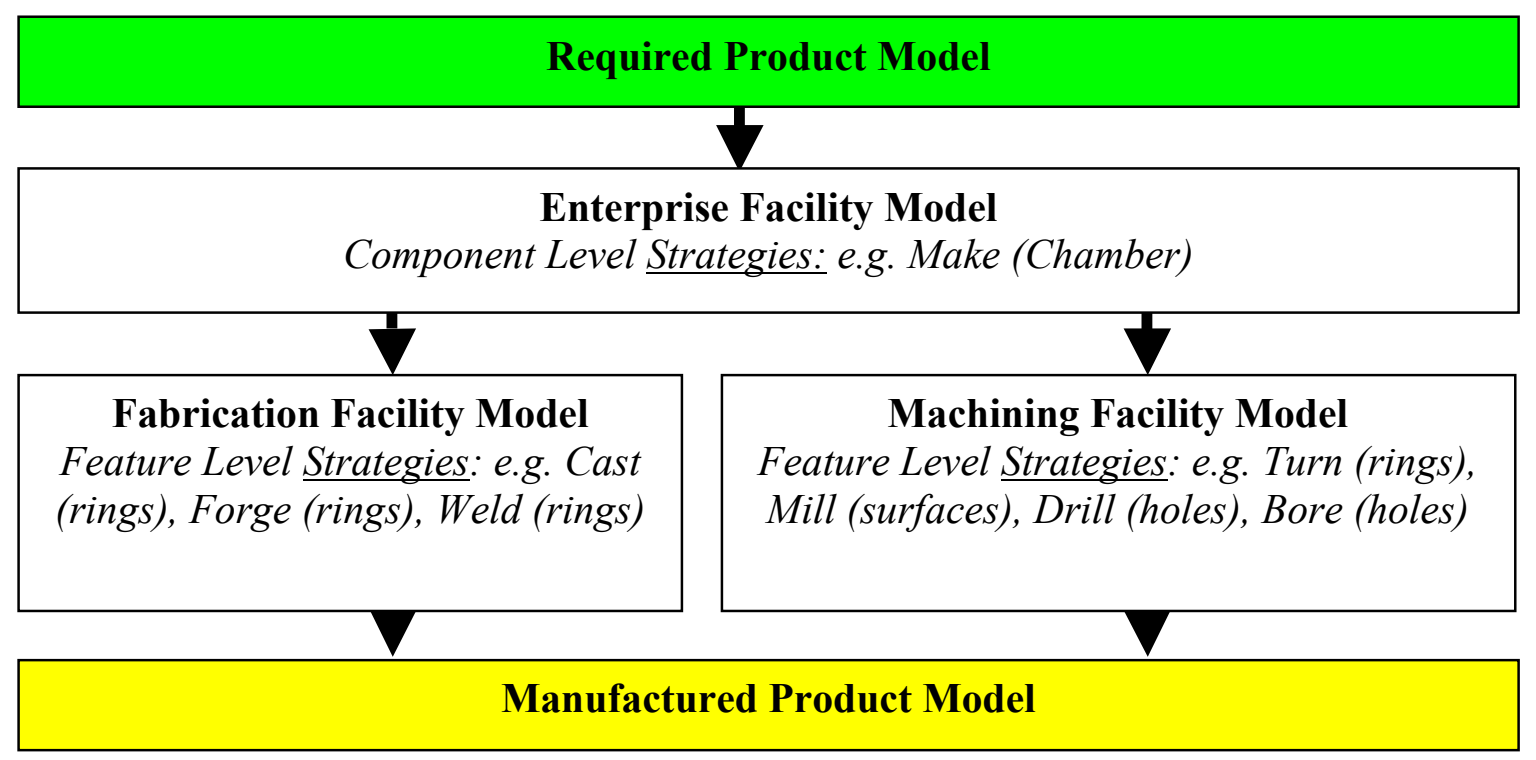

Figure 6: The Layering of Manufacturing Strategies

specific manufactured features, e.g. holes, grooves, and rings.

The higher component level of strategy is responsible for combining sequences of low level strategies. These are influenced by a model of the required product (with values often extracted from a CAD database). Individual low level strategies then create and manipulate a separate product model representing what has actually been manufactured (where values are determined by process capabilities).

The goal of the higher level strategy is to align the required and manufactured product models. Higher level strategies also consider the whole component and manufacturing enterprise.

It is here that this work differs from the hierarchy of strategies described by Molina and Bell (1999) (also shown in figure 1). Many of their examples show descriptions of when and where to use a particular facility included in the facility class itself. For example, the strategies table for a "rotational parts station" includes the following statement: "if a component requires only turning processes, this station should not be used". The coding style example in figure 4 shows a similar rule for selecting individual processes (rather than specific machines).

It was found through the experimental work (described in section 5) that including this type of rule in a set of strategies for a facility directly limited reuse. The problem can be further explained by the turning process example. The rule as stated above makes several assumptions about the whole manufacturing enterprise. It assumes for example that an alternative station is available to turn components, and that this machine should be used in preference to the multi-function station being described.

This assumption prevents the facility representation from being reused in enterprises with no such alternative. It also limits the ability of a decision support system to interpret conflicting business objectives. The single function station may for example be cheaper, but slower. If lead time is more important that cost, then the multi-function station may be the better option. Either way this type of decision can not be taken at the level of an individual 
station, as it requires an understanding of the whole manufacturing enterprise.

It was also found that a more in-depth understanding of why stations are used in certain circumstances is required. It was found better to limit the scope of station strategies to generating performance indices (e.g. process durations, resource demands, and costs) which are can be interpreted at the enterprise level. The above turning rule example could then be restated according to constraints set at the enterprise level, e.g. use the lowest cost
The Make(Chamber) shown in figure 6 strategy is responsible for sequencing a series of low level fabrication and machining strategies. Several drilling strategies may for example be available (using different machine tools with different mounting and tolerance capabilities). The Make(Chamber) strategy will therefore need to decide which drilling strategy should be applied. This requires an examination of the whole product requirement. Holes on the inside of a series of rings may for example require a specific mounting, which can access these more

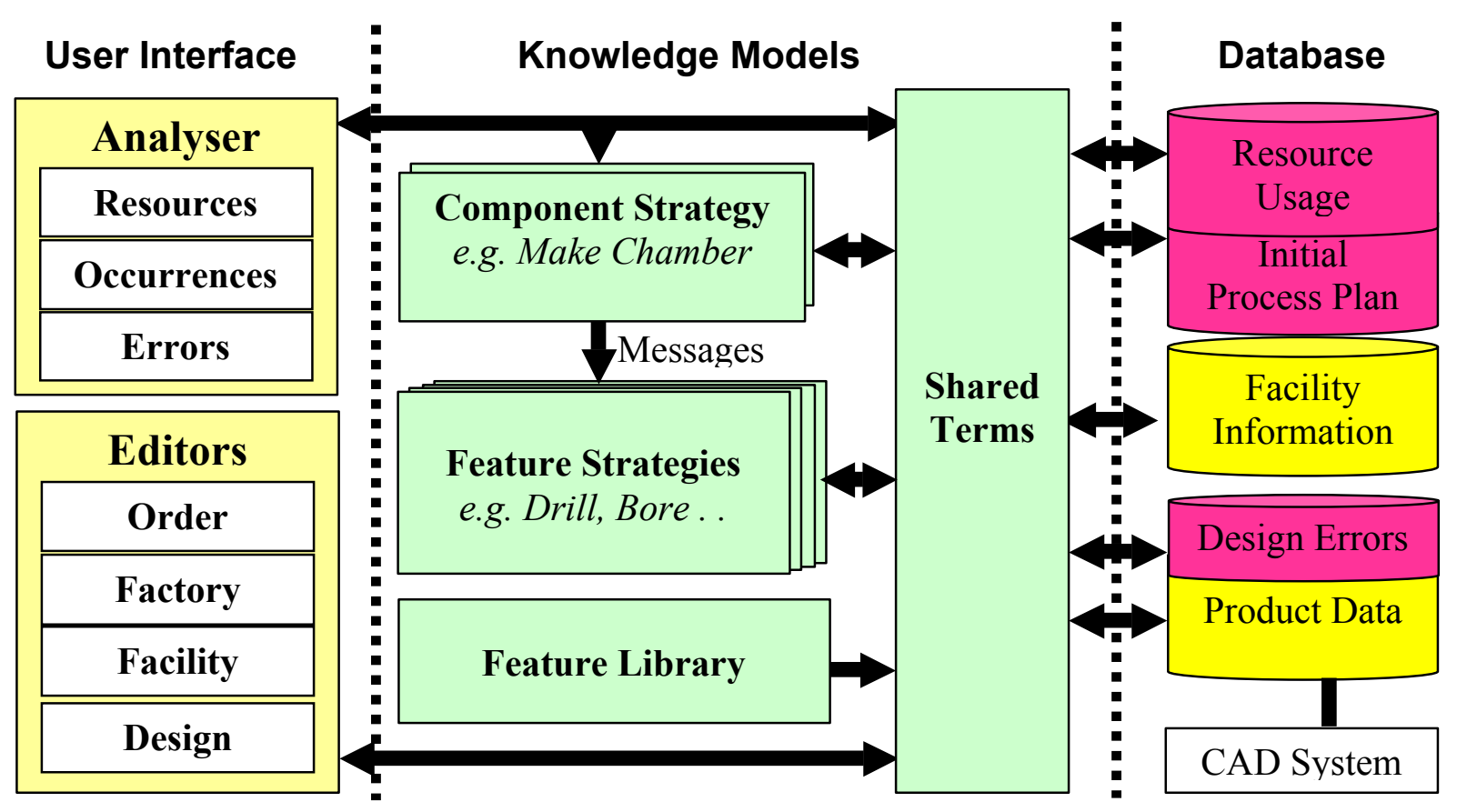

Figure 7: Manufacturability Analysis Platform (MAP)

stations that meets the specification, use single function stations in preference to multifunction stations wherever possible, and/or minimise lead times.

Returning to the combustion chamber example, feature level strategies may include milling holes, and turning rings. These strategies are only executed when a controlling component level strategy decides that they achieve its required objectives. Feature level strategies therefore maintain no concept of when they should (or should not be applied). difficult locations.

The advantage of using separate levels of strategy become apparent when high level strategies consistently reuse sets of low level feature strategies. The distinction between low and high level strategies is determined by the reusability of the feature level representations, i.e. do they make good building blocks for component level strategies? They should also make no assumptions about the availability of other facilities in an enterprise, and the business 
criteria for selecting one facility over another.

\section{Experimental Platform}

The Manufacturability Analysis Platform (see figure 7) has been used to test and evaluate the principles described above. Manufacturing strategies are expressed by as series of shared terms (implemented as Java methods). These support the description of product attributes, processes, and the relationships between feature requirements and processes. Models of standard features (e.g. cylinders and holes) can also be referenced by the shared methods, along with customised models for bespoke features.

The MAP uses a tiered architecture to separate information (stored in relational databases and/or spreadsheet tables) from knowledge (coded in Java and expressed using the shared methods). The platform also implements required and

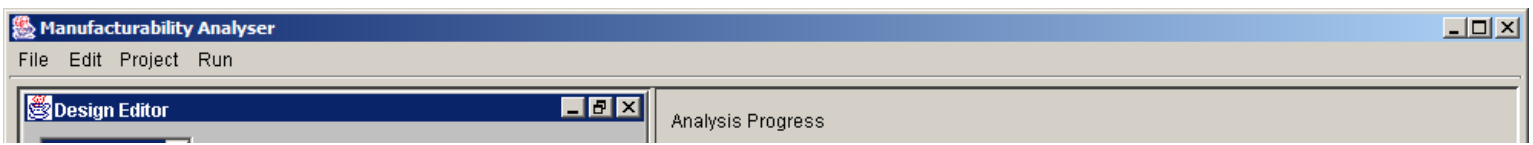

manufactured product models (see figure 6); and reuse issues have been further considered when locating rules and constraints between layers of manufacturing strategies, and product representations. The current experimental implementation is based on the use of Excel spread sheets as information repositories combined with Java code.

Figure 8 shows a screen shot of the user interface, and the results of a strategy simulation. The top left box allows users to configure both product requirements and manufacturing enterprises. The bottom box shows details of any errors in manufacturing strategies, the timings associated with process occurrences, and the resources demanded by processes.

In developing this platform reuse has been demonstrated by its ability to support multiple component strategies from a common set of low level feature strategies. Several of these high level strategies can be selected via the user interface.

The separation of manufacturing strategies from information also allows multiple machine tool and material settings to be simulated by a single strategy.

\section{Conclusions}

A review of existing literature on the representation of manufacturing knowledge highlighted the need for application guidelines on the classification of knowledge for optimum reuse. This paper provides these guidelines by developing three principles for the improved reusability, i.e. the separation of information from rules and constraints, the separation of product knowledge from manufacturing process knowledge, and the layering of manufacturing strategies. Each of these concepts has been tested using the Manufacturability Analysis Platform, and a case study based on a jet engine combustor casing. Further work is required to test these concepts on more complex representations of product and manufacturing processes, and to implement these modelling guidelines in an industrial design environment (rather than an experimental platform).

\section{Acknowledgements}

This work is part of an ongoing research project entitled "Knowledge Representation and Reuse for Predictive Design and Manufacturing Evaluation”. This has been funded under EPSRC GR/R64483/01, and actively supported by Rolls Royce plc.

\section{References}

Guerra D, 2004. A Manufacturing Model to Enable Knowledge Maintenance in 
Decision Support Systems. PhD Thesis, Loughborough University, UK

Harding J. 1996. A knowledge representation model to support concurrent engineering teamwork. $\mathrm{PhD}$ Thesis, Loughborough University, UK

ISO/IEC 10746-1: Reference Model for Open Distributed Processing.

Kosanke K, Vernadant F, and Zelm M., 1999, CIMOSA: enterprise engineering and integration. Computers in Industry, 40, 83-97.

Lin H, Harding J, Shahbaz M, 2004.

Manufacturing system engineering ontology for semantic interoperability across extended project teams. Int. J. Production. Research, 15 December 2004, vol. 42, no. 24, 5099-5118.

Liu S, Young R, 2004. Utilizing information and knowledge models to support global manufacturing coordination decisions. Integrated Journal of Computer Integrated Manufacturing, September 2004, Vol. 17, No. 6, 479-492.

Maropoulos, P.G. 2003. Digital enterprise technology - defining perspectives and research priorities. International Journal of Computer Integrated Manufacturing, 2003, 16(7-8): 467-478.

Molina A, Bell R, 1999. A Manufacturing Model representation of a flexible manufacturing facility. Journal of Engineering Manufacture: Proceedings of the Institution of Mechanical Engineers, Vol 213, Part B, pp.225-246.

Mills J, Goossenaerts J, 2001. Towards Information and Knowledge in Product Realisation Infrastructures. International Federation for Information Processing, Publications IFIP.

Oldham, K, Kneebone, S, Callot, M, Murton, A and Brimble, R, in N.

Mårtensson, R. Mackay and S. Björgvinsson (eds.), 1998. Changing the Ways We Work. Advances in Design and Manufacturing, Vol 8, Proceedings of the
Conference on Integration in Manufacturing, Göteborg, Sweden, IOS Press, Amsterdam, October 1998, 198-207. Accessed 01/Jun/04:

http://www.kbe.cov.ac.uk/moka

Schreiber G, Akkermans H, Anjewierden A, de Hoog R, Shadbolt N, Van de Velde W, Wielinga B, December 1999. The CommonKADS Methodology. ISBN 0262-19300-0. http://www.commonkads.uva.nl

Wray R, Lisse S, Beard J, 2004. Ontology infrastructure for execution-oriented autonomous agents. Robotics and Autonomous Systems 49 (2004) 113-122.

Young, R.I., Dorador, J.M., Cheung, W.M. and Zhao, J., 2000, "A manufacturing infrastructure to link team based design to global manufacture", The $4^{\text {th }}$ International Conference on Design of Information Infrastructure Systems for Manufacture, CD-Rom paper 329, Melbourne, Australia, November 2000.

Young R I M, Guerra D, Gunendran G, Das B, Cochrane S, Cutting-Decelle A-F, 2005. "Sharing manufacturing Information and Knowledge in Design Decision Support" Advances in integrated design and manufacturing in mechanical engineering ed A. Bramley, D Brissaud, D Coutellier, $\mathrm{C}$ McMahon. Pub Springer, 2005, pp173-188. ISBN 1-4020-3481-4

Zhao J, Cheung W, Young R, 1999. A consistent manufacturing data model to support virtual enterprises. Int. Journal of Agile Management Systems 1/3 [1999] 150-158 